\title{
Historic District Conservation Based on the Concept of Cultural Ecology - Case Study of Xi'an Bei Yuan Men Historic District in China
}

\author{
Hongyan Li, Siqi Ling \\ Department of Architecture, Faculty of Human Settlement and Civil Engineering, Xi' an Jiao-tong University, Xi'an, China
}

Email address:

lihy04@126.com (Hongyan Li), 1298504953@qq.com (Siqi Ling)

To cite this article:

Hongyan Li, Siqi Ling. Historic District Conservation Based on the Concept of Cultural Ecology — Case Study of Xi'an Bei Yuan Men Historic District in China. Science Research. Vol. 4, No. 5, 2016, pp. 120-125. doi: 10.11648/j.sr.20160405.13

Received: November 11, 2016; Accepted: December 5, 2016; Published: December 7, 2016

\begin{abstract}
This paper discusses conservation of historic districts based on the concept of cultural ecology. In this paper, we analyze the protection status of Xi'an Bei Yuan Men historic district in three fundamental characteristics of culture, mainly including territorial culture, non-renewable feature and continuity. It's to propose a solution to coordinate contradiction between the protection of the cultural characteristics and meet the requirements of residents on social development. In this process, the paper argues that policy guidance has a very important role. It advocates that any social development should be based on the protection of the cultural ecology of the region.
\end{abstract}

Keywords: Cultural Ecology, Historic District, Conservation

\section{Introduction}

Under the background of rapid urbanization, the traditional culture has been threatened heavily. The protection of cultural ecology has gradually been paid more attention. The cultural ecology was proposed by American culture and human expert Steward in 1955. He stressed the influence of environment on social culture system. The United Nations Educational, scientific and cultural organization held a meeting in Hangzhou in May 2013 with the theme of "culture the key to sustainable development", and released the Hangzhou declaration: culture and sustainable development [1].

Zhouhai Zhong analyzes the current situation and existing problems of Gannan Hakka ancient village, and put forward several suggestions on village protection on the view of cultural ecology [2]. Yaolong Wang analyzes the art of the south China garden on the view of culture ecology in three aspects of natural environment, population and background, and exotic culture collision [3]. Xiaofeng Dong analyzes the characteristics and problems of resources in the north Zongbu Alley area, and puts forward the protection and utilization way on the cultural ecology systems of the former residences of celebrities related theories, according to the "census - evaluation - carding - protection — reuse" path [4].

In this paper, Xi'an Bei Yuan Men Historic District as an example, the analysis discusses the historical block protection based on ecological culture.

Xi'an Bei Yuan Men Historic District is located in the northern part of the old city in the center of Xi'an, nearby the Bell Tower and Drum Tower, and it's about 4 hectares. Huimin district is Muslim communities, Bei Yuan Men Historic District is Hui mainly centralized residence, formed with a strong Muslim cultural atmosphere in this historic district.

Xi'an Bei Yuan Men Historic District have already appeared in the Sui and Tang Dynasties, and it was in the front of Chancery Front Gate, belongs to the scope of Imperial City. In the Tang Dynasty "rebellion", imperial court calmed the insurgency down by the power of Arabia and Western soldiers. After that, those soldiers stay in Chang'an, which came into being Xi'an Hui Fang gradually, and formed unique Hui style of the Xi'an Bei Yuan Men Historic District. When it came to the Northern Song Dynasty, Hui began to live here, lived on doing business. Bei Yuan Men District is formed in this period. After the completion of the mosque, Hui lived at the periphery of the temple. Hui lived here today, and formed a unique Moslem habitation in Xi'an. 


\section{The Origin and Characteristics of Cultural Ecology}

Cultural ecology comes from the development of ecology, which is proposed by German biologist E. H. Haeckel in the 1870s. His study is about the relationship between organisms and the environment (Including non-biological environment and biological environment). The word, cultural ecology, originated from ecology, was put forward as early as 1377 in the Introduction of The History written by Ibn Khaldun. The author emphasized human cultural links with the surrounding environment. In the first half of the 20th century, parts of American anthropologist believed that environment directly or may determines culture, for example, when F Boas and A Kroeber made their study on the indigenous peoples of North America, such as the Indians. They opened up study to cultural ecology [5]. In 1955, Julian Steward put forward the concept of "cultural ecology" in his book Theory of Culture Change. This book is believed to be a symbol of the birth of cultural ecology [6]. The main content of study is the relationship between culture and the environment [7]. Cultural ecology is a new cross subject in the field of cultural studies, and it is a scientific research on the resources, environment, state and law of the existence and development of culture. Stewart believes that culture is adaption, and highlights the dynamic characteristics of culture. The word "adaption" uses a term in the theory of biological evolution, and it has nothing to do with the laws of biology. Adaption means human cultural adaptation. The process of adaptation is a creative and active activity [8].

When cultural ecology is proposed, the original research was conducted by anthropologists. The main content is to study the interaction between human culture and natural environment. The understanding of the traditional cultural ecology of environment is mainly limited to the natural environment. With the development of science and technology, the arrival of the information age makes the research scope and direction of cultural ecology extended to every field. The main purpose of cultural ecology is to explain the process of cultural adaptation to the environment.

In the early stage of culture, the meaning of culture contains dynamic characteristics. The use of "ecology" in Cultural ecology is a direct expression of that culture is changing with the changing environment. It shows that there are similarities between culture and nature. Culture has its environmental background, and the internal order and law of its changes [9].

Ecological culture reflects that culture is continuously changing with the change of the environment, with some fundamental characteristics such as territorial culture, non-renewable feature and continuity, etc.

Territorial culture implies that each place has its own features, in terms of both physical aspects such as street pattern, building structure, and cultural aspects such as local custom, identity, etc. Regional natural environment and social environment are closely linked. For example, in the Bei Yuan Men district, local people have their own religion, so mosques are very important to their daily life. Consequently, it is of vital importance to keep the mosques in a proper way.

Non renewable refers to culture has its own specific historical nature and social environment, which is not reproducible. Once the culture disappears, it will not be regenerated. It's just like what Ruskin wrote in his famous book named Seven lamps of Architecture: "That which I have above insisted upon as the life of the whole, that spirit which is given only by the hand and eye of the workman, never can be recalled. Another spirit may be given by another time, and it is then a new building; but the spirit of the dead workman cannot be summoned up, and commended to direct other hands, and other thoughts. " [10]

Continuity refers that culture is dynamic and need to keep pace with the times. Each culture is developed gradually in history. Difference culture layers accumulate in their localities. It is very important to continue a place's own culture since it has direct impact on people's "root" feeling. Although cities and towns are developing very fast in recent years, especially in China, people should not forget the past and traditional culture should not be interrupted.

\section{Existing Problems of Xi'an Bei Yuan Men Historic District}

Xi'an Bei Yuan Men Historic District (also called the Muslim District) is situated in the center part of Xi'an (Figure 1), with traditional Chinese architectural style, and strong cultural atmosphere of the Muslims (the Muslims are also called the Huis in China) at the same time. It's the performance of integration of Islamic culture and Chinese traditional cultural. And it reflected that the Hui culture make adaptive changes under the influence of the Han culture in the long historical process, which explains the cultural adaptability of the cultural ecology. About 60,000 people live in the area, one third of which are the Huis and the others are the majority Hans. The complete texture of streets and the suitable street scale create effective communication space. And its traffic accessibility is good. Some buildings, such as the Great Mosque (Figure 2; It was built in the Tang Dynasty, and still in use.), the Bei Yuan Men No.144 Gao courtyard (Figure 3; It was built in the Ming Dynasty, and now used as a visiting place of interest.) and Huajue Lane No.125 Mr. An's courtyard (Figure 4; It was built in the late Qing Dynasty, and now a resident.) have been well preserved. However, with the social economic development, many buildings have been damaged heavily. The phenomenon of illegal building house is serious. Illegal building house not only exist fire and other security risks, the style has also been a lot of damage.

So there is an urgent need to protect the territorial culture of the historic district. 


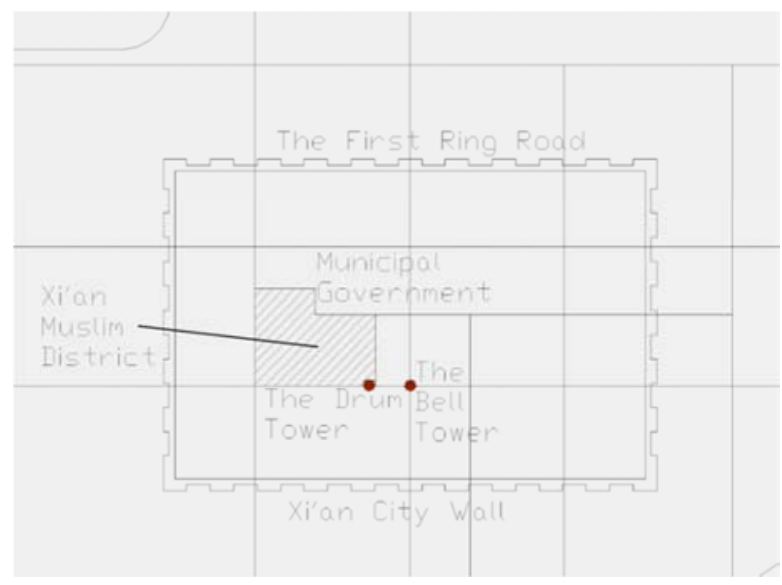

Figure 1. Location of the Muslim District.

\subsection{Loss of local Characteristics}

Muslim feature of the Huajue Lane in Xi'an Bei Yuan Men Historic District is very distinct. The Great Mosque is located there, surrounded by former local Muslims houses, with Chinese traditional style of the Ming and Qing Dynasties. In recent years, the population growth is much faster than housing units' provision. Traditional courtyards are disappearing. New houses are constructed without considering building regulations. In order to facilitate visitors shopping, the roadway is stamped with a canopy (Figure 5). In the daytime, it attracts many tourists, but it people moves away the commodities, the gates with aluminum Alloy material and high cement steps appear, which is not in harmony with the traditional atmosphere of the historic district (Figure 6).

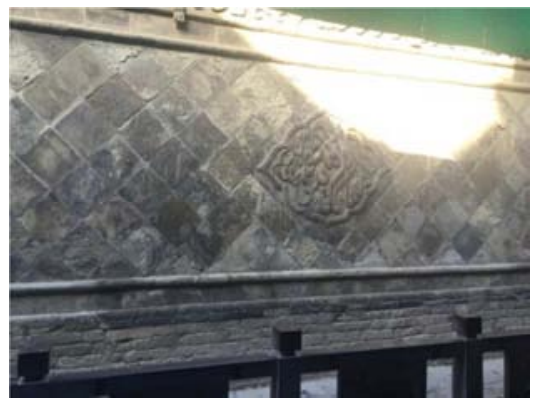

Figure 2. Great Mosque.

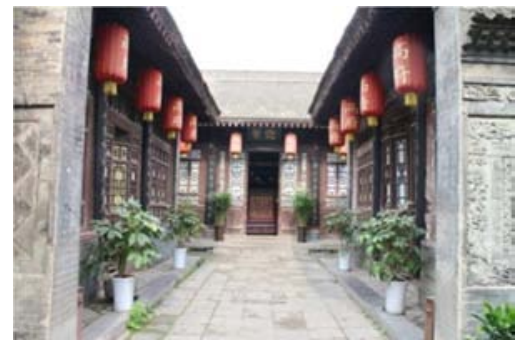

Figure 3. Bei Yuan Men No. 144 Gao courtyard [11].

\subsection{Ignorance of Continuity}

The formation, development and change of culture are gradual, not overnight. The characteristics of Xi'an Bei Yuan Men Historic District are influenced by modern architecture.
Some newly added building abandoned traditional architectural style (Figure 7), which has caused the loss of historical information in the old streets. Construction of historical information is lost, the new building can't reflects the integration of Islamic culture and Chinese traditional culture in the historical process.

\subsection{Threats to the Development of Muslim Culture}

Islam is the religion of the Huis. There has a rich and colorful Muslim culture in Hui's settlement. However, in Huajue Lane, the width of only two people in parallel, some residents in order to expand the living space, construct two or three layers of floor on both sides of the alley. The distance between the floors is very narrow; the closest part is less than one meter (Figure 8). The alley lost sunshine and traditional Muslim flavor. Some residents in the Muslim District have no convenient water supply and drainage system.

On the north side of the Great Mosque, there are still some remnants of former traces. In the morning, people sing in the mosques. The atmosphere of the streets is quiet and warm. Several Hui elderly people sit on the south side of the alley and chat with each other. The sun shines into the alley and the old mottled walls sobbed about the passing of history in the shadow.
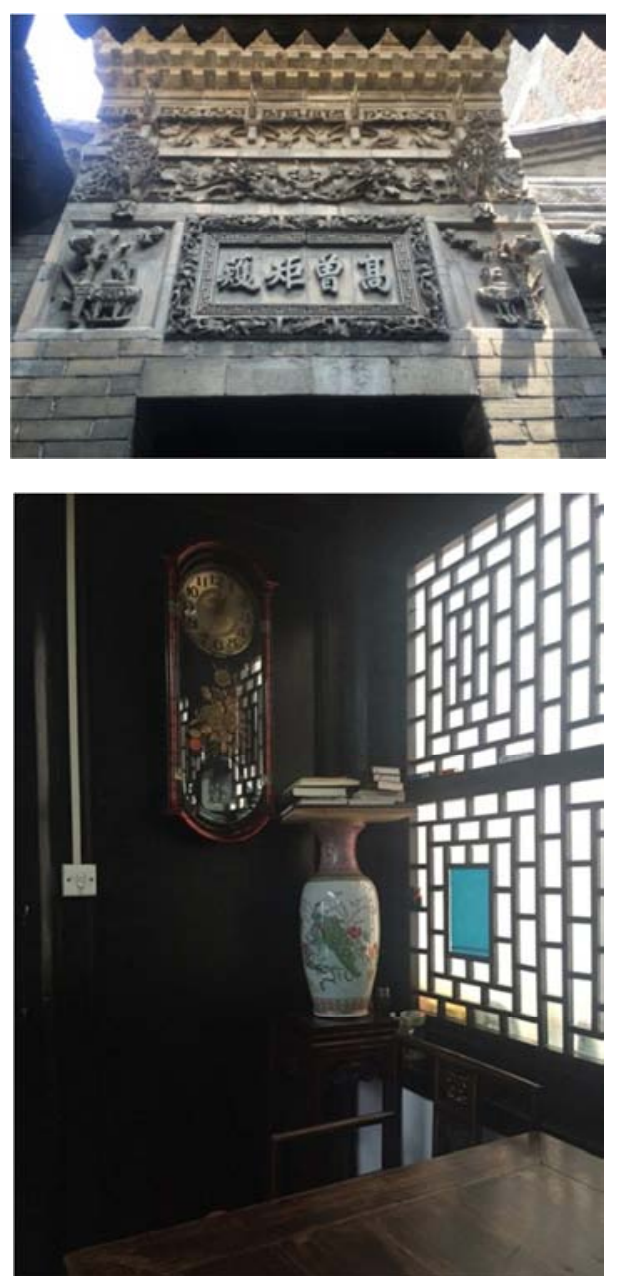

Figure 4. The front gate of Huajue Lane No.125 Mr. An's courtyard and it's interior decoration. 


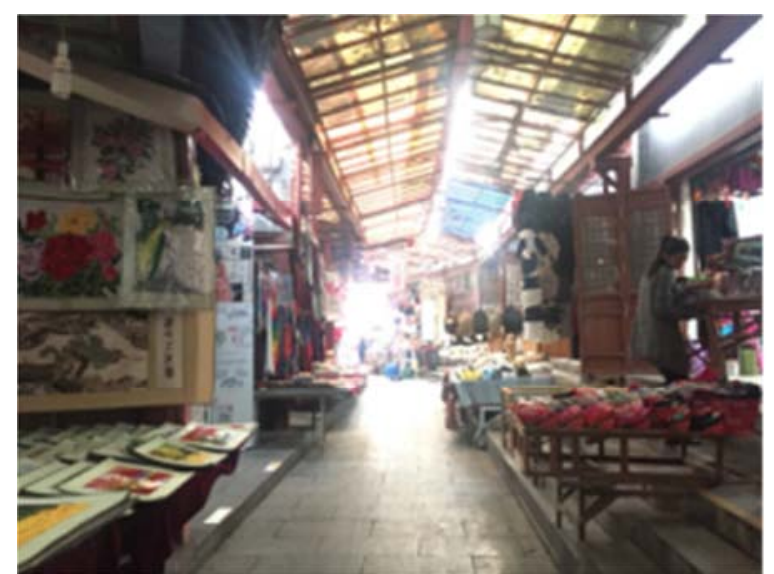

Figure 5. Streetscape of Huajue Lane.

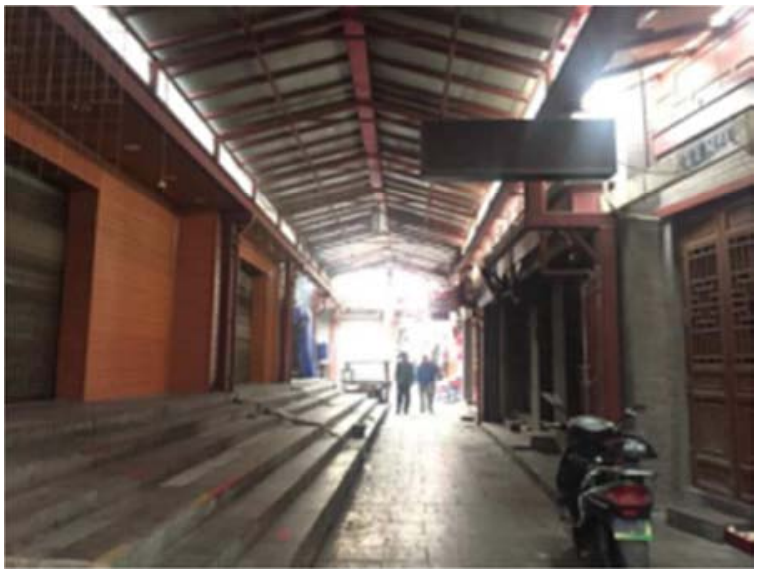

Figure 6. HueJue Lane without business

\section{Historic District Conservation from the Perspective of Cultural Ecology}

\subsection{Public Space for Collective Life}

Starting from the concept of cultural ecology, it is important to provide public communication spaces for local people. "Public space is the place for public facilities, services and functions. It is the place of expression of collective life in its social, economic dimensions. Public space is the place of collective memory. It allows the access, practice, preservation of the monuments in a city, which are the common historical and cultural heritages of the group" [12]. In the Bei Yuan Men District, it is necessary to keep the identity of each street, namely, Bei Yuan Men Street traditional culture, restaurant; Xi Yang Shi Street - restaurant, butcher, Muslim snacks; Hua Jue Alley - souvenir, etc. This is very important to protect the Hui's culture and the Hui people's life since running small business is a main profession for many Huis. Moreover, open space are needed in this historic district. A small open space could give the long and narrow street a 'breath'. After walking along a shopping street, people will feel fresh by seeing the green area or having a cup of tea.

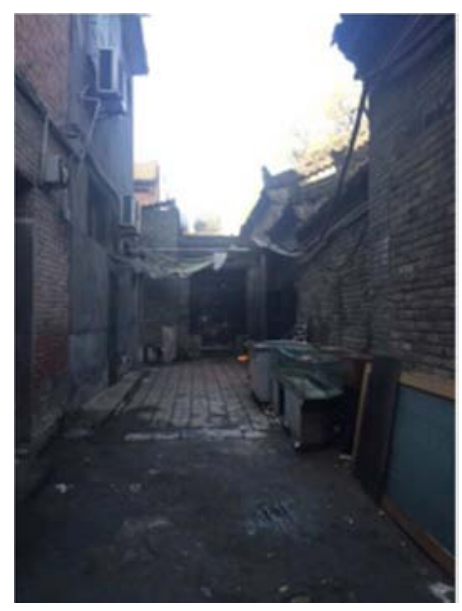

Figure 7. Some new buildings in the district.

\subsection{Territorial Development in Terms of Housing Improvement}

Cultural ecology emphasizes on territorial development, so it is important to conserve local features in terms of physical and social culture. A critical question is how to improve the housing situation of the district. Most of the buildings along the Bei Yuan Men Street were one or two storey wooden-structured buildings with Ming or Qing Dynasty's architectural style. 'The buildings represent the typical houses and commercial building tradition of Northwest China' (Xi'an City Planning and Design Institute, 2002: 86). Some basic principles should be held in the improvement process. (1) Respect the Hui people's custom and religious belief in planning and architectural design; (2) Retain traditional building style and courtyard structure, protect the integrity of overall historical atmosphere and keep low building height to protect the townscape of the area; (3) Adjust the usage of land to get a bigger housing capacity. Consider family-based businesses and mixed land use in planning efforts; (4) Applying multiple methods in preservation and renewal to avoid massive eviction; (5) Improve environment and install infrastructure by public agencies.

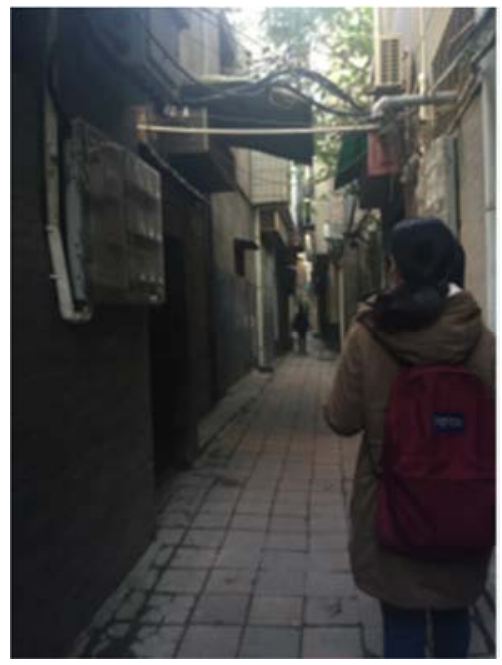

Figure 8. The narrow alley. 


\subsection{Conservation of Traditional Courtyard Structure}

Courtyard structure is a traditional way for Chinese housing. However, only very few traditional courtyards were left in China today and the main building form has transformed to parallel pattern and point pattern. Professor $\mathrm{Wu}$ [13] advocates the recovery of traditional culture in a famous project called 'Juer Hutong' in Beijing. According to $\mathrm{Wu}$ [13], courtyard structure houses could achieve higher living space comparing to parallel pattern and point pattern for two or three storey buildings. Furthermore, the common yard is a natural meeting 'hall'. Usually people know each other within a common courtyard. They are acquainted with each other and care for each other.

The Beijing 'Juer Hutong' project could be a good example for the future housing development of the Muslim District. The successful implementation of the 'Juer Hutong' project shows that modernization does not have to sacrifice the historical value of houses. With architects' careful design, traditional organic housing structure could be preserved and modern life standard could be achieved (Wu, 1994).

The experience is applicable in the Muslim District since low-rise building and courtyard structure are the main feature of the district in terms of physical aspect. It is helpful to solve the contradiction between traditional culture protection and local people's housing need.

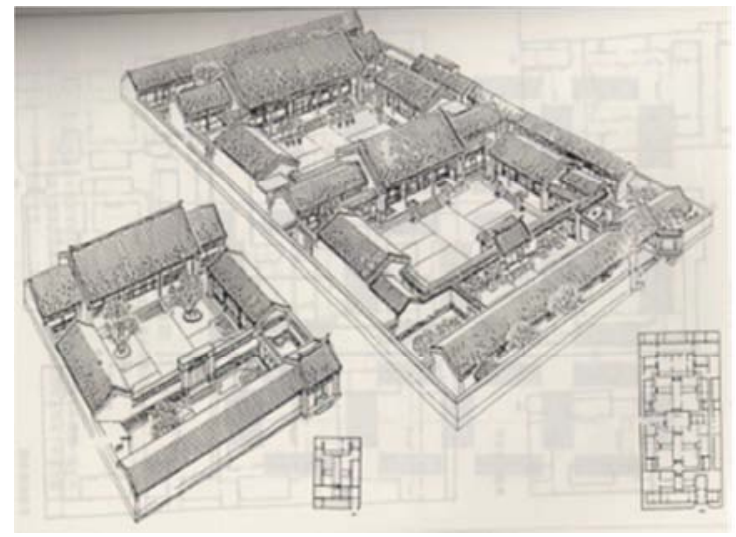

Figure 9. A typical traditional courtyard in Beijing (source: Wu [13], 1994: 87).

\section{Policy Support and Guidance}

Policy environment has direct guidance role to human behavior patterns. For example, before the implementation of land nationalization policy, land ownership belong to the individual, and brothers divided their properties by number of rooms; However, after the implementation of the policy, land ownership gradually returned to the state, at this time, brothers in the separation of property pay more attention to the division of land area. This reflects the impact of policy on the feelings of the people, thereby changing the behavior of people, so as to achieve the purpose of policy makers. So pay attention to the historical block protection policy guidance is very important for the historical district protection.

Meanwhile, historical buildings often appear all kinds of problems and need to repair and maintenance after several generations. To restore a historic building need a lot of money, sometimes even higher than reconstruction. Most residents are unable to afford the restoration fee. Therefore, the protection of historical buildings needs government and enterprise investment.

Consequently, laws and regulations are important to the development of a historic district. On the one hand, through legislation, it is possible to enforce the implementation of historic district protection. On the other hand, a realistic development plan respecting local cultural ecology is imperative in Xi'an Bei Yuan Men district. At the same time, it is also important to strengthen supervision, which can ensure the implementation of laws, regulations and plans in a right way.

\section{Conclusions}

Under the background of environmental issues under the global attention, the ecological environment of historic district should be paid more attention, which includes both natural ecological environment and cultural ecological protection. Some traditional districts in China are accompanied by economic backwardness and other practical issues. Under the impact of modern life mode, people pursue the life quality, many traditional buildings and historic districts are facing the danger of being destroyed. Some history courtyard has been transformed beyond recognition. The rich and vivid pattern of courtyard has ceased to exist. Therefore, from the concept of cultural ecology, the protection of the historic district of space features and cultural characteristics has an important role in the continuity of the history and culture. At present, we need to increase the public's protection consciousness, and protect the non renewable valuable resources of historic districts.

\section{Acknowledgements}

The article is supported by the Soft Science Foundation of Shaanxi (No.:2016KRM106)

\section{References}

[1] Li Hongyan. Understanding Space of Historic Towns Based on Cultural Ecology - Case Study on Gepai Historic Town of Lantian, Shaanxi [J]. Architectural Journal, 2015, (3): 81-85.

[2] Zhouhai Zhong. Gannan Hakka Ancient Village Protection on View of Cultural Ecology [J]. Journal of Anhui Agri. Sci. 2013, 41 (16): 7232-7234.

[3] Yaolong Wang. South China Landscape: in the view of Cultural Ecology [J]. Journal of Northwest Forestry University, 2014, 29 (2): 288-292.

[4] Xiaofeng Dong. Research on the Protection and Utilization of the Cultural and Ecological Systems in the Former Residences of Celebrities-A Case Study of LIANG LIN's Residence Zongbu Alley Area in Beijing [J]. Chinese Landscape Architecture, 2014, 04: 75-78. 
[5] Ji Douyong. Sketches for Cultural Ecology [J]. Journal of Foshan University (Social Science Edition), 2004, 22 (5): 1-7.

[6] Huang Yufu. Interdisciplinary Research in Twentieth Century -- Cultural Ecology [J]. Social Sciences Abroad, 1999, (6) 19-25.

[7] Yang Wenan. Stewart and cultural ecology [J]. Journal of Yunnan College of Education, 1993, 9 (1): 92-96.

[8] Julian H. Steward. Theory of Culture Change: The Methodology of Multilinear Evolution [M]. Urbana: University of Illinois Press, 1955.

[9] Hou Chuanwen. Relativity and universality of culture [J]. Science Economy Society, 1999, 17 (4): 64-66.
[10] Ruskin. Liu Yuerong edit, Zhang Lin translate. Seven lamps of Architecture [M]. Jinan: Shandong Pictorial Publishing House, 2006, p. 174.

[11] http://you.ctrip.com/sight/xiuyan2140/73059-dianping528429 13.html. 2016-11-2.

[12] Loubes, Jean Paul. Public Space, Drum Tower Muslim District, Xi'an, China, Project Report 3-97, NTNU, 1997.

[13] Wu Liangyong. The Old City of Beijing and Its Juer Hutong Neighborhood. Architectural Industry Publish Press of China, ISBN 7-112-02396-3, 1994. 